\title{
TRAINING OF TRAINERS AT OPERATIONAL AND STRATEGIC LEVELS
}

\author{
Grudi ANGELOV, Dimitar TASHKOV, Emil ENEV \\ “G. S. Rakovski” National Defence College, Sofia, Bulgaria \\ g.angelov@armf.bg, d_tashkov@abv.bg, emilenev1966@abv.bg
}

\begin{abstract}
At the beginning of the twenty-first century, understanding of transformation encompasses not only organizational and structural processes, but also processes related to the literacy of those who deal with transformation. The paper does not analyze the literal meaning of the concept of literacy as reading and writing abilities. Within the Armed Forces system, literacy can be considered from several aspects - doctrinal, managerial, methodological, psychological, pedagogical and technical. Since transformation is not an one-time act, but a permanent function of the National Security System, it is necessary to emphasize the importance of the continuity of the process of developing literacy of today's leaders. The purpose of this paper is to present some of the arguments for the need of transformation of literacy (knowledge and skills) of the leaders of the transformation processes at the operational and tactical levels, so that they are able to skillfully apply the modern technological innovations in the preparation of the management bodies of the Armed Forces.
\end{abstract}

\section{Keywords: decision, education, management, manager, training}

\section{Introduction}

In response to the constantly changing and unpredictable threats to national interests and security, the Armed Forces need to maintain readiness to conduct operations which are characterized with great diversity and at the same time to transform their structure and concepts in order to develop capabilities for response to threats and to achieve adequate combat power. The constant need for changes necessitates higher requirements for the Armed Forces training system.

Transformation is not restricted to structures and the number of servicemen only. This is not the essence of the transformation process. The real transformation is the change of thinking, the change in the perception of the problems, and the search for new ways of solving the problems that cannot be solved with the current methods.

The main directions of the process of transformation in the training of officers, staffs and troops will be analysed through a wider kaleidoscope. We will try to take into account the influence of the contemporary sciences, methodologies and technologies on the preparation of the Bulgarian Army leadership in the following aspects: skills and abilities of military leaders and commanders to deal with threats for which they have not been prepared; compliance of the training system of the Armed Forces with the new training requirements; the ability of the officers to take advantage of the new technologies in the process of training and education. The commanders at strategic and operational levels play the principal role in these processes. 
1. Fundamentals of the management of the system for training in the security sphere.

The management of education and training in the security sphere has its place as a specific type of educational management with its own research field, purpose, tasks, subject, methods and means of research and practical realization. The outline of the scientific parameters of this specific type of educational management gives grounds for concluding that among the diverse range of managers, there is room for one more:

educational manager in the field of security and defense.

\subsection{Profile of the educational manager}

Who is this manager? It can be summed up that this is the person who directly manages the fulfillment of the task at his/her level (strategic or operational). This means that, similarly to other managers, he/she will perform the following:

- will direct the people who are responsible for the result - motivate, guide, control; will resolve conflicts; will be the leader; will monitor group dynamics; will take care of the growth and development of people motivating them for additional education or qualification;

- will manage the work - will develop plans and strategies, set objectives and make decisions on their implementation, will establish teams for task execution, will evaluate results (will plan and design, organize and control systems development and their current status);

- will manage the unit responsible for the relevant management level (from the organization as a whole to a team for a particular task);

- will manage processes, operations and task activities - this is part of the work management - will design, program, control the specific activity, will make managerial decisions applying appropriate systems and methods, will control and ensure the quality of the preparation and performance of tasks. In the field of trainer's education, like any other sphere, there are different levels of management and different managers respectively:

- At strategic level, the role of managers is given to those authorized to manage the security and defense system;

- At the level of institutions which offer adult education services, there may be several ranks: senior manager (and their team); "middle-level" manager - unit (e.g. faculty at university) or department manager in an institution (e.g. human resources manager), "low-level" manager (e.g. course organizer);

- At the level of educational process management - the manager's role is taken by the trainers or the leader of the team of trainers (when the training is conducted by such a team).

- Each level takes into account the different requirements of the positions, roles and functions of the education and training manager.

1.2. The subject of the educational management

In particular, in the system (sector) of training of trainers/instructors, the subject of the management activity is:

- At strategic level - manager training in the security system;

- At operational level - competitiveness of the Armed Forces as an Institution;

- At the level of education and training the educational process with the trainers learners such as commanders and managers within the three levels in the Armed Forces system.

The subject of trainer's education management is the functions and roles of partners in the trainer's education system and partners in the training process, as well as the interaction of the educational institution for adult education with the external security environment. In particular, the subject of the management activities of educational managers at different levels of management in the national security system is:

- At strategic level - the full and flawless functioning of the system of training the managers for their role as trainers; 
- At operational level - endurance and sustainability (competitiveness) of the Armed Forces as an Institution and preservation of its good image;

- At the management level of the educational process - ensuring all conditions for successful completion of the pre-set objectives and tasks of the particular course; quality and effective training of trainers.

In general, the goal of the management activities of educational managers at different levels of education management of trainers is to achieve stability, quality and efficiency of the functioning of:

- The defense training system, as well as implementation of modern state policy in this field;

- Institutions providing educational services for adults in the field of security and defense;

- Development of the qualification system.

\subsection{Main tasks of the educational managers}

In connection with the goal, the main tasks of the educational managers at different levels of management of trainers' education are specified:

- Strategic, tactical and operational management of the training system for trainers,

- Developing "working" modern strategies and policies to ensure the effective functioning of the training system for trainers;

- Development of policy and system for validation of self-acquired competencies by adult learners;

- Developing adequate modern legislation to facilitate the realization of global and European priorities (strategies and trends) for lifelong learning and extended-to-life learning;

- Developing methods of financing the educational activities with adult learners;

- Studying the needs of the market for adult education services in line with the current priorities and trends;

- Studying the needs of the security system and of the Armed Forces in particular, aiming at organizing and supporting adult education services.

\section{Place, role and tasks of the trainer in the Armed Forces.}

What are the specifics of the current trends in training and what are the requirements for the trainers?

In order to fulfill the requirements of optimality and efficiency in the preparation and engagement of the Armed Forces, it is necessary to provide flexibility and adaptability of their elements. The analysis of the core functions defined in the regulatory documents shows that command and control is the very combat function that must provide the military units as a system with the necessary flexibility, resilience and reaction ability to external influences. It means that its continuous adaptation to the conditions of the operations is necessary. This flexibility is required for both the controlling and the controlled subsystems within the system.

The basic needs of the Security System and of the Armed Forces which arise from the specifics of their use, are depicted in Figure 1 [2]. Depending on the environment in which these systems will operate, strategic and operational managing bodies must be capable to apply both passive and active adaptation measures to the system.

The research of doctrinal and scientific sources has shown that two main types of adaptive responses of the systems - active and passive - can be defined. Active adaptation is a process whereby the unit itself changes its environment while passive adaptation is when the unit changes its own behavior or structure to act more effectively in a changing environment. Although a positive process, adaptation is accompanied by activities related to changes, the results of which may be expected, but can also lead to unexpected consequences. For this reason, in both cases (active or passive), management should guide the adaptation process, which realizes the control system on the managed system. This reduces the risk of the negative impact of entropy 
brought into the system by the environment and eliminates the risk of additional entropy generated in the system itself.

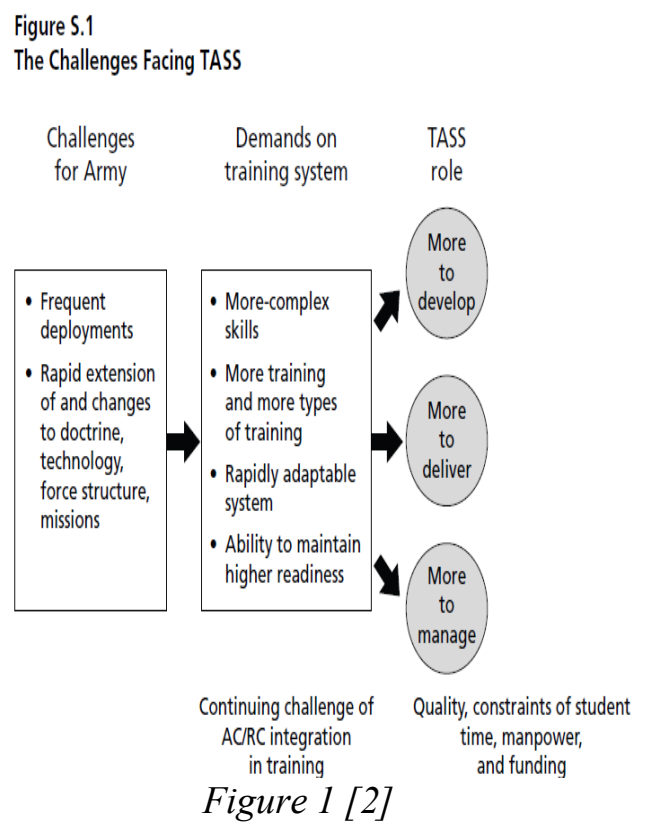

The management impact is achieved through the respective method and approach of command of the military formations. All activities in the system of maneuver units are aimed at achieving certain goals. They are set on the basis of the tasks assigned by the higher ranking systems, the environmental parameters, and the actual capabilities of the system.

Execution of the command and control decision, as an element of the command and control model, may not lead to the exact desired end-state and the achievement of the expected results. It is even possible, for reasons of objective and subjective nature, to increase the degree of entropy and the relatively balanced state of the system to be distorted more as a result of a particular management decision. Certain additional factors, of course, should be taken into account, such as the staff that assists the commander in making the decision and in its realization, and the commander's experience. Essential to the operational levels is the influence, impact or lack of: intent; allocation of roles and responsibilities; restrictions on actions; preliminary evaluations including alternative changes in the plan; the nature of the interactions of the participants in the conflict; the allocation of resources, which includes:

- information;

- personnel;

- material resources.

One of the main functions of the command is the control function, which the trainers have to implement continuously. It gives the opportunity to receive constant feedback both on the results of the actions of the managed subsystem and on the results of the actions of the control subsystem. Thus, the control allows for the permanent determination of the necessary measures to correct the- behavior of the systems and hence the quality of performance, which is an indicator of the quality of the command-management processes.

The control is carried out in two main directions - regarding the performance of the management functions (or the management entity) and the other activities in the organization (or the object of command and control). The control evaluates deviations from the normal mode of operation of the managed object, and the deviations are arranged according to their significance for reaching the planned state; the causes and factors of deviations are revealed; control determines the causes and factors (based on their significance) for the occurrence of the deviations. The control is exercised over: the fulfillment of the planned tasks and activities; compliance with internal regulations concerning of the behavior of the entity being managed; the specific tasks of the plan; compliance with legal acts; the implementation of management decisions, etc.

The aim of the control is to ensure the implementation of the activities, the achievement of the desired results and the realization of the set goals. It is "a key management function that has the task of determining the degree of goal realization, the on-going flow of the process, and the 
state of the external factors that affect the system (the managed entity)" [1].

Execution of the management decision may not lead to the exact desired end-state and to the achievement of the expected results. The nature of the operational use of maneuver units and the analysis of the behavior of the subjects in the implementation of the management function justifies the following reasons for differentiating the following groups of reasons for not achieving the desired results: criteria for success of the decision; the logic of the decision; risk assessment; personal qualities.

The first group of reasons for not achieving the desired results is related to the lack of flexibility of decisions. The analysis of the decisions made by the commanders and the bodies for command and control in the course of the command and staff trainings and exercises shows that the most common error in the practical solution of problematic situations is the lack of ability to compare the planned with the current situation, hence lack of data and decision-making capabilities during the operations and also, if necessary, changing the original plan.

The clear and precise definition of success criteria, as a second group, is a mandatory condition that can be considered as a separate stage or phase in the decision cycle due to the vague nature of the actions of the participants in the operations. This is realized in the following aspects: the first aspect includes the social considerations which are the basis on which decisions are taken in the conduct of operations; the second aspect reflects the complex nature of the operating environment and can be referred to as a complex criterion; the third aspect focuses on the specific feature of operations when there is a likelihood of transition from combat to non-combat missions and vice versa.

The second direction related to the assessment of the command and control decision is the determination and prevention of risk. Each solution contains a certain amount of risk. Solutions with a high amount of risk have a potentially powerful effect. Conversely, decisions containing a small amount of risk have potentially little effect.

The logical aspect is the third category connected with the assessment of the command and control decision. The analysis of the behavior of the commanders of maneuver units in the course of the conducted exercises shows that one of the main mistakes is that in finding a solution of a certain situation (decision-making) the commanders always impose their own logic, sometimes even without being aware of that.

The fourth group of reasons for the absence of rationality of the decision is related to personal qualities. The analysis of the behavior of the officers in the course of the exercises shows that some personal qualities of the superiors in the chain of command, among which the qualities for analytical (rational) work and impulsivity, are of great importance,

In any case, as a result of the command and control decisions taken, the elements of the military unit, considered as a system, react, the relations between them change, and some of the variables of the system, which can describe its condition change, acquire new qualitative and quantitative characteristics. Consequently, as the system transitions to a new state, a certain result (positive or negative) is achieved. The question is whether we can have objective, rather than subjective, information about the most likely outcome of the effect of the command and control decision, and how we can get this information. The analysis of documents related to the training and preparation of human resources and the leadership of military and non-military systems in particular, shows that the risk of increasing subjective influence on the system for command and control can be avoided when the Armed Forces become a self-training organization.

A learning organization is such a structure which, despite the difficulties 
encountered, can actively shape its own future. This kind of capability is only possible when the organization has a mechanism which allows learning to be realized at each level and from each activity being conducted. Training is one of the most important activities offering an endless range of learning opportunities from one's own experience. From this perspective, the increasing pace and chaos on the battlefield results in increasing need to learn quickly without direct supervision, monitoring and guidance.

\section{Conclusion}

In summary, this report shows that the challenges to the military science and education are various. Armed Forces objective to become a learning organization in these conditions can be achieved by fulfilling the requirement of learning from experience. In order to better understand and take advantage of these learning opportunities, the well-established professionalism of the army and the trend for mission command to be applied on an individual level, the training system should be focused on learning from lessons learned in the preparation phase.
For this reason, through using the methodology of the system approach to learning, during the training design phase, trainers are required to see the learning event through the trainee's perspective (be aware of the learner's level of awareness and expertise - to understand their current state) and to answer the question of how these learners can acquire as many abilities as possible from this class. On the other hand, trainees should be aware of their trainer's intentions. This requires commanders of all levels, in their role as trainers, to set clear and coherent learning objectives before the start of the training, i.e. the very philosophy of conducting the training throughout the chain should be understood by all. A fundamental requirement for all methodologies and curricula is that tasks are repeatedly performed to ensure the achievement of the necessary level and quality of knowledge and skills. The difference between these methodologies is in the philosophy of the applied repetitions. Repeated performance must not be based on the benefit of achieving a result, standard or norm, but should be based on the understanding of the problem or on the need to meet certain regulatory requirements.

\section{References}

[1] Magazine (Magazine "Strategies of educational policy", 2001)" - subject edition “Adult's education", 4, 2001, p.113.

[2] Transformation and The Army School System, Michael G. Shanley, James C. Crowley, Matthew W. Lewis, Ralph Masi, Susan G. Straus, Kristin J. Leuschner, Steven Hartman, Sue Stockly, Published by the RAND Corporation, Pittsburgh, RAND URL: http://www.rand.org/, p.12-15. 